N. J. ENFIELD (MPI, Nijmegen)

\title{
Nominal classification in Lao: a sketch*
}

\begin{abstract}
Speakers of Lao (Southwestern Tai, Laos) use a number of forms of nominal classification, including numeral classifiers, modifier classifiers, class terms, and kin prefixes. The numeral classifier system is a typologically prototypical one, with dozens of classifiers making fine semantic distinctions in the context of enumeration. Repeater constructions are common, making numeral classifiers an open class. The modifier classifier system involves the use of classifiers in nominal modification of all kinds, including demonstratives (in situational or discourse deixis and anaphora), attributive modifiers (such as adjectives and relative clauses), and a unitizing construction resembling noun classifier constructions found in other languages. The class term system is lexically derivational, with hundreds of nouns incorporating a prefixed term expressing taxonomic essence (e.g. whether the noun denotes a tree, insect, some kind of liquid, and so on). The kin prefix system involves the prefixation of kinship terms and other human terms as prefixes to personal names. This paper is the first general description of nominal classification in Lao. While the system is almost exactly the same as that found in closely related Thai, many former descriptions of that language have concentrated on numeral classifier constructions only, and have neglected a significant distinction suggested here, namely that between numeral and modifier classifiers.
\end{abstract}

\section{Introduction}

Lao (Southwestern Tai, Laos/Thailand/Cambodia) is the national language of Laos (ENFIELD 1999), spoken by around four million people in Laos, with varieties spoken in northeast Thailand and northeast Cambodia. Lao is an isolating language with no productive grammatical affixation (such as case-marking or agreement inflection) and little productive derivational morphology. Tense, number, and gender are not grammatically marked. Aspectual distinctions are made by various "deverbal" markers (i.e. subordinate elements which elsewhere function as full verbs) and a handful of dedicated verbal operators (such as a marker of negation and some adverbs). Noun phrases are head-initial. Lao is a topic-prominent language, freely allowing nominal ellipsis and making generous use of multi-verb sequences to manage clausal grammar. There are five lexical tones.

The purpose of this paper is to sketch the systems of nominal classification used by speakers of Lao, with the aim to make an empirical contribution in light of recent advances in the universal typology of nominal classification (Grinevald 1993, 1996, 2000; AIKHENVALD 2000). This is the first general description of nominal classification in Lao. Lao features four systems of nominal classification: numeral classifiers, modifier classifiers, class terms, and kin prefixes. Numeral classifiers form a large set (up to 100 members) and

* I thank Sasha Aixhenvald, Tony Diller, and Frank Seifart for very helpful comments on a draft of this paper. I would also like to thank ColETtE GRINEvald for early advice and encouragement in approaching this topic. I gratefully acknowledge the Max Planck Society's support of this research. 
include repeaters, thus constituting an open class. These are discussed in $\S 2$, below. Modifier classifiers occur with nominal modifiers such as demonstratives, adjectives, and relative clauses. While many numeral classifiers may be used in this function, many of the usual numeral classifier distinctions are not observed, and in most cases just two classifiers are used (namely too $^{3}$ 'body' and $q a n^{3}$ 'small thing'). The assignment to nouns of these two classifiers in numeral classifier constructions is constrained by shape/form specific semantics, but when they are used as modifier classifiers, their semantics are much more abstract. Modifier classifiers are discussed in $\$ 3$. Class terms form a smallish set (twenty or so members). These are bound derivational elements in the lexicon, denoting some taxonomic feature of their referent. They are described in $\S 4$. Kin prefixes are a limited set of kinship terms which combine with personal names to derive terms of address. These are described in $\S 5$. In $\S 6$, some remarks are made about relationships between various forms of nominal classification, and $\S 7$ presents a summary of the descriptive content of the paper.

\section{Numeral classifiers}

Lao numeral classifiers show properties of typologically prototypical numeral classifier systems (cf. Aikhenvald 2000: 98 ff., Grinevald 2000: 63-64). That is, they "appear contiguous to numerals in numeral noun phrases and expressions of quantity" and "do not have to appear on any constituent outside the numeral NP" (AIKHENVALd 2000: 98). Numeral classifiers are a well-noted areal feature of mainland Southeast Asia, and the Lao system is a typical one.

\subsection{The basic numeral classifier construction}

The following example illustrates the standard pattern for enumerating countable entities, in which a noun phrase consists of the main noun (which names the thing being counted ${ }^{1}$ followed by the numeral and an appropriate numeral classifier:

$\begin{array}{lllll}\text { (1) } k u u^{3} & \text { sùù }^{4} & \mathrm{paa}^{3} & \text { sòòng' } & \text { too }^{3} \\ \text { 1sG.NONP buy fish } & \text { two } & \text { CLF.ANIM } \\ & \text { 'I bought two fish.' }\end{array}$

The classifier used here is $t o o^{3}$, which is also used as a numeral classifier for animals of all kinds (but not humans), and which as a main noun means 'body' (and in that usage can refer to the body of a person as well as that of an animal). The numeral and classifier form a unit distinct from the main noun in the noun phrase, as shown by the possibility of inserting an adjunct between the main noun and the numeral-plus-classifier combination:

(2) $k u u^{3} \quad s u u^{4} \mathrm{paa}^{3} \quad j u u^{l}$ talaat $^{5}$ sòng ${ }^{3}$ too $^{3}$
1sG.NONP buy fish be.at market two CLF.ANIM
'I bought fish at the market, two (of them).' (= 'I bought two fish at the market.')

1 I use the term "main noun" to refer to the semantically specific nominal which names the referent. The term "head" is problematic. Grammatically, the "head" of the noun phrase is probably the classifier element (since it is obligatory, and is the element which hosts most if not all nominal marking such as specifiers, determiners, modifiers, etc.; cf. SACKMANn 2000 on Mandarin Chinese). Semantically, "head" is a more appropriate term for the main noun, with its more specific meaning. 
In this case, the phrase sòng ${ }^{3}$ too $^{3}$ 'two CLF.ANIM' is separated from the noun it is semantically associated with, and is placed into the "afterthought" position, to the right of the clause. Note that the Lao sentence is a perfectly normal way of saying 'I bought two fish at the market', and has nothing of the marked quality shown by the first English free translation given in (2). ${ }^{2}$ Further demonstration of the independence of the main noun from the numeral-plus-classifier combination is that the main noun can be (and very often is) ellipsed, when the referent is contextually retrievable:

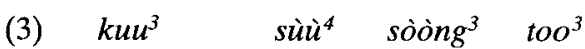

1SG.NONP buy two CLF.ANIM

'I bought two (e.g. fish).

When the numeral is nùng 'one', two orders are possible for numeral and classifier.

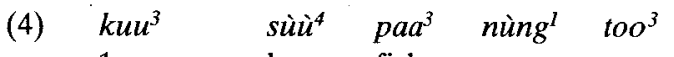

1sG.NONP buy fish one CLF.ANIM

'I bought one fish.'

(5) $\quad \mathrm{kuu}^{3} \quad \mathrm{sùu}^{4} \quad \mathrm{paa}^{3} \quad$ too $^{3} \quad$ nùngl

1sG.NONP buy fish CLF.ANIM one

'I bought a fish.'

No other numeral allows the classifier-numeral ordering given in example (5). ${ }^{3}$ As the English translations of examples (4) and (5) suggest, when the numeral nùng 'one' appears after the classifier, it functions as a determiner (i.e. a non-specific marker of a singular entity), appearing in the same slot as demonstratives. Thus, in (5), the classifier is functioning as a modifier classifier (see $\S 3$, below), and, accordingly, it is de-stressed in that position.

While numeral classifiers are virtually obligatory when counting things, speakers may very occasionally omit the classifier: ${ }^{4}$

$\begin{array}{llll}\text { (6) } k u u^{3} & \text { sùù } & p^{4} a^{3} & \text { sòòng } \\ \text { 1sG.NONP buy fish two } & \text { fou } \\ \text { 'I bought two fish.' } & \end{array}$

However, in the context of asking 'how many' - using $c a k^{2}$ 'how many' in the pre-classifier numeral position - a classifier is obligatory:

$\begin{array}{lllll}\text { (7) } \text { mùng }^{2} & \text { sùŭ } & \left(\text { paa }^{3}\right) & c a k^{2} & *\left(t o o^{3}\right) \\ \text { 2sG.NONP buy fish how.many } & \text { CLF.ANIM } \\ \text { 'How many (fish) did you buy?' } & \end{array}$

Note also that a number of other quantifiers, such as baang 'some', thuk $k^{1}$ 'every', $t \grave{e}^{0} . l a^{0}$ 'each and every' also require numeral classifiers, appearing in the same constructional pattern as numeral classifier expressions:

2 It can be said that noun phrases in Lao are "non-configurational", i.e. "flat" in constituent structure terms, a feature which can be associated generally with numeral classifier languages (GIL 1987).

3 Almost all nominal modifying elements in Lao follow the noun, unlike numerals greater than one. Rare exceptions include quantifiers such as baang 'some' (as in baang ${ }^{3}$ khon $^{2}$ [some person/people] 'some people').

${ }^{4}$ It is unclear why speakers omit the classifier in these rare cases. 
(8)

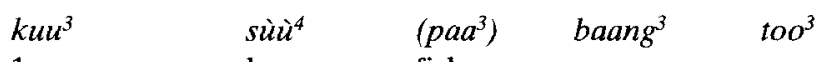
1SG.NONP buy fish some CLF.ANIM 'I bought some (of the fish).'

(9) $k u u^{3}$

$\begin{array}{lllll}k u u^{3} & s \grave{\iota_{i}}{ }^{4} & \left(p a a^{3}\right) & t h u k^{1} & t o o^{3} \\ \text { 1sG.NONP } & \text { buy } & \text { fish } & \text { every } & \text { CLF.ANIM }\end{array}$
'I bought every one (of the fish).'

\begin{tabular}{|c|c|c|c|c|}
\hline$k u u^{3}$ & $\operatorname{sùu} u^{4}$ & $\left(p a a^{3}\right)$ & $t e^{0} \cdot l a^{0}$ & $t o o^{3}$ \\
\hline 1SG.NONP & buy & fish & each.and.every & CLF.ANIM \\
\hline
\end{tabular}

\subsection{Repeaters}

Hundreds of Lao nouns, especially those referring to familiar and/or common objects, are conventionally assigned a particular numeral classifier. But there are also many cases in which no numeral classifier is conventionally assigned to a given noun, and it is common in such cases for a noun to be used to "classify itself", i.e. to appear as both the main noun and the numeral classifier. In the following example, hang ' 'nest' is used, in this way, as a "repeater" classifier:

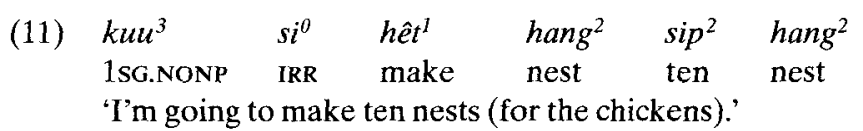

A common situation in which a repeater is used is when the main noun is also a numeral classifier itself (i.e. a semantically general term specified as the numeral classifier for some set of nouns). In the next example, the main noun is khon ' 'person/people', which also serves as the classifier used for any nominal referring to a person:

$\begin{array}{lllll}\text { (12) } k u u^{2} & h e n^{3} & k h o n^{2} & \text { sòòng } & k^{3} h n^{2} \\ \text { lsG.NONP } & \text { see } & \text { person } & \text { two } & \text { CLF.HUM } \\ \text { 'I saw two people.' } & & & \end{array}$

Note, however, that speakers would often omit the first instance of $k h$ h $^{2}$ 'person/ people' in this example, presumably because it is so obviously redundant. Compare example (12) (in which $k k^{2} n^{2}$ is used as both main noun and numeral classifier) with the following example, in which the main noun is $k h u u^{2}$ 'teacher' (and $k h o n^{2}$ is simply used as a numeral classifier for this human noun):

$\begin{array}{lllll}k u u^{2} & h e \hat{n} n^{3} & k h u u^{2} & \text { sòong } & \text { khon } \\ \text { 1sG.NONP see } & \text { teacher } & \text { two } & \text { CLF.HUM } \\ \text { 'I saw two teachers.' } & & & \end{array}$

The repeater strategy is the closest thing to a residue option in the numeral classifier system. While Lao has two numeral classifiers with very general semantics ( qan $^{3}$ 'small thing' and $\operatorname{too}^{3}$ 'body'), these are not genuinely "residue" options, since despite their semantic generality and wide applicability they do have specified shape/form semantics and thus are restricted in the range of nouns they can occur with. They cannot be used, for 
example, in counting things which have no shape, such as samnuan' 'expression'. In this case, only a repeater strategy may be used: ${ }^{5}$

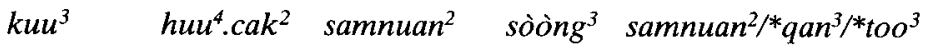

$$
\begin{aligned}
& \text { 1sG.NONP know expression two expression/CLF.SMALL.THING/CLF.ANIM } \\
& \text { 'I know two expressions.' }
\end{aligned}
$$

The classifiers $\operatorname{too}^{3}$ 'body' and $q a n^{3}$ 'small thing' have much broader semantic applicability when used as modifier classifiers, and in those functions could both be used with reference to samnuan ${ }^{2}$ 'expression' (and virtually any other noun; cf. § 3, below).

Thus, it seems preferable to regard the repeater strategy as a genuine residue option in numeral classification, since it can be used with any nominal whenever it is not obvious what the appropriate numeral classifier is. However, if a given noun normally takes a particular numeral classifier, then that classifier will be the one used, and a repeater construction would be odd or unacceptable. The next example shows that to use $l o t^{l}$ 'vehicle' as a repeater for the noun lot $^{1}$ 'vehicle' is not possible, since it is pre-empted by the classifier $k h a n^{2}$, which is the conventional and only numeral classifier used for vehicles:
(15) $k u u^{2}$
$l a k^{1}$
$\operatorname{lot}^{1}$
sò̀ng ${ }^{3}$
khan $^{2 / *} \operatorname{lot}^{1}$
1sG.NONP steal
vehicle two
CLF.VEHICLE/vehicle

'I stole two cars.'

\subsection{The set of numeral classifiers}

The class of words which may function as numeral classifiers is large. KERR (1972) lists over 80 dedicated classifiers, and this is certainly not exhaustive. The numeral classifiers are semantically heterogeneous, expressing distinctions of shape, size, material, texture, measure, and social value. Here is a representative list of some common numeral classifiers:

\begin{tabular}{|l|l|l|}
\hline Classifier & $\begin{array}{l}\text { Meaning as } \\
\text { noun }\end{array}$ & Semantics and example referents \\
\hline$k \grave{o} n^{4}$ & 'lump' & lumps of mass which naturally occur (e.g. pieces of ice, rocks) \\
\hline sên $^{5}$ & 'line' & ribbon/strip/cord-shaped things (e.g. roads, cables) \\
\hline khon $^{2}$ & 'person' & people, excluding monks (e.g.teachers, children, men) \\
\hline too $^{3}$ & 'body' & non-human entities with 'bodies' (e.g.dogs, snakes, shirts) \\
\hline ton $^{4}$ & 'plant' & living plants (e.g. bushes, shrubs, trees) \\
\hline tòòn $^{1}$ & 'piece, hunk' & lumps of soft mass which are hewn (e.g. pieces of meat) \\
\hline
\end{tabular}

Table 1: Some common numeral classifiers

\footnotetext{
5 In fact, it is likely that the speaker would simply omit the first "main noun" use, giving $k u u^{3} h u u^{4} \cdot c a k^{2}$ sòong ${ }^{3}$ samnuan $^{2}$ [1sG know two expression] 'I know two expressions'.
} 
Continue Table 1

\begin{tabular}{|l|l|l|}
\hline Classifier & $\begin{array}{l}\text { Meaning as } \\
\text { noun }\end{array}$ & Semantics and example referents \\
\hline nuaj & 'unit' & round things, assembled things (e.g. apples, chairs, mountains) \\
\hline phùùn $^{3}$ & 'soft sheet' & cloths and similar objects (e.g. tablecloths, skirts, tarpaulins) \\
\hline phèèn $^{I}$ & 'stiff sheet' & stiff/hard flat things (e.g. sheets of dried noodle, LP records) \\
\hline khan $^{2}$ & 'handle' & $\begin{array}{l}\text { things with handles, operated by hand (e.g. vehicles, um- } \\
\text { brellas) }\end{array}$ \\
\hline mêt $^{l}$ & 'grain' & very small grains (e.g. seeds, specks) \\
\hline lam $^{2}$ & - & very large cylindrical things (e.g. tree-trunks, boats, airplanes) \\
\hline lang $^{3}$ & 'back' & houses, certain fish traps \\
\hline hua $^{3}$ & 'head' & books, non-fruit bulbous vegetables \\
\hline qan $^{3}$ & - & small things which can be held in hand \\
\hline
\end{tabular}

Table 1: Some common numeral classifiers

While the classifiers in Table 1 can each be used in expressions of enumeration of a large number of nouns, there are also many numeral classifiers with restricted application - i.e. assigned to just one noun or to a very narrow semantic range. Here are a few examples:

\begin{tabular}{|l|l|l|}
\hline Classifier & $\begin{array}{l}\text { Meaning as } \\
\text { noun }\end{array}$ & Example referents \\
\hline daang $^{3}$ & $\begin{array}{l}\text { 'square fish } \\
\text { net for dipping' }\end{array}$ & any net with evenly spaced holes (fish nets, mosquito nets) \\
\hline lêm $^{5}$ & - & teeth, candles \\
\hline qong $^{3}$ & - & monks \\
\hline taa $^{3}$ & 'eye' & rice seedling-beds \\
\hline maan $^{2}$ & 'ear of grain' & corn cobs, rice 'ears' \\
\hline
\end{tabular}

Table 2: Some numeral classifiers of restricted semantics

As the discussion so far suggests, it is not clear that a well-delimited set of numeral classifiers can be defined. First, most of the words which are regarded as numeral classifiers - by virtue of the fact that they can appear in the numeral classifier 'slot' - also function as independent nouns in other grammatical contexts. One may ask whether words like $k_{h o n}{ }^{2}$ 'person' are polysemous (i.e. in one sense a regular noun meaning 'person/people', and in a second, more grammatical sense, a numeral classifier for humans), or whether they represent a single lexical entry which adopts a classifier function by virtue of its appearance in a certain kind of construction. 
Second, while many nouns are conventionally associated with just one numeral classifier (e.g. the numeral classifier for vehicles is always $k h a n^{2}$, for fruits always nuaj ${ }^{1}$ ), there are many cases of inter- and intra-speaker variation in choice of numeral classifier for certain nouns, depending on a range of factors. One source of variation is the interaction of numeral classifiers with speech level phenomena. For example, KERR (1972: xxiii) lists two different numeral classifiers which may be used for counting monks: huup ${ }^{4}$ (elsewhere meaning 'image') and qong ${ }^{3}$ (with no independent meaning). The most common numeral classifier used for monks is $q o n g^{3}$, with huu ${ }^{4}$ having a considerably more formal air. Further, speakers occasionally use $k h o n^{2}$, the regular numeral classifier for people, although this is invariably recognized, upon reflection, as "incorrect". A second source of variation in selection of numeral classifier arises from the fact that many nouns (especially new words for culturally non-traditional objects) have no dedicated or conventionalized classifier, resulting in various different classifiers being equally applicable on the basis of semantic appropriateness. For example, a stapler might be counted using nuaj $^{l}$ (elsewhere used for things which are assembled as "units") or $q \mathrm{an}^{3}$ (elsewhere used for any kind of small thing which can be held in the hands). A pair of trousers may be counted using $t o o^{3}$ (elsewhere a noun "body" and a classifier for all non-human animates) or phùùn" 'soft sheet' (a classifier for any piece of cloth).

A third source of variation is perhaps harder to pin down, but it seems to depend on what aspect of the entity being counted is "focused on" by the speaker. For example, the

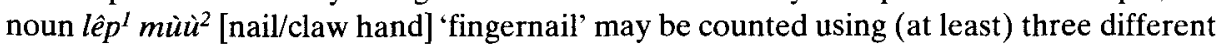
elements in the numeral classifier slot:

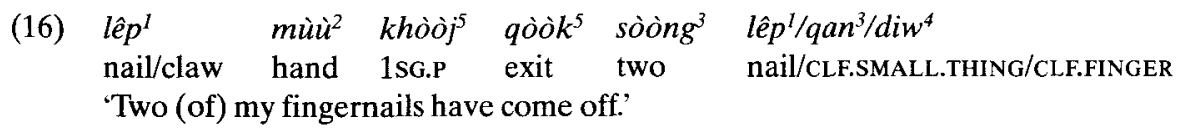

The first choice is a repeater, while the second categorizes the fingernails as 'small things'. The third choice given here - diw ${ }^{4}$ 'finger' - is not a classifier in semantic terms. Semantically, $d i w^{4}$ 'finger' does not categorize 'fingernail' in terms of, say, shape. Rather, the 'fingernail' is part of the 'finger' (or, perhaps, the 'finger' is the location of the 'fingernail'). The use of a location term in a classifier slot can also be observed in the conventional use of bùang 'side' to count symmetrically paired body parts such as arms or eyes:

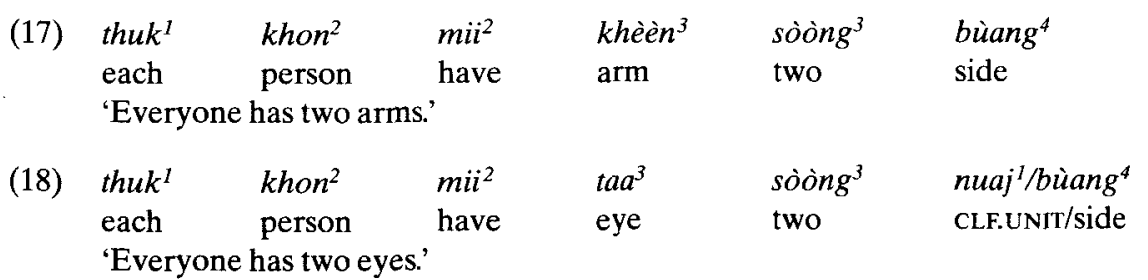

In the case of $t_{a} a^{3}$ 'eyes', shown in example (18), speakers have a choice between using the classifier $n u a j^{1}$ (used for round things, fruits, and assembled units) or the locational term bùang ' 'side'. In the case of 'arms', 'legs', and 'ears', only bùang' 'side' (or a synonym $k^{k}$ han $^{5}$ ) may be used in the numeral classifier slot. Note also that a repeater could be used in the case of (17), since there is no conventional numeral classifier for arms. Here is a text

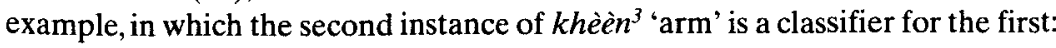




\begin{tabular}{|c|c|c|c|c|c|c|c|}
\hline $\begin{array}{l}m i^{2} \\
\text { there.is }\end{array}$ & $\begin{array}{l}k^{k h o n^{2}} \\
\text { person }\end{array}$ & $\begin{array}{l}m a a^{2} \\
\text { come }\end{array}$ & $\begin{array}{l}\text { tat } \\
\text { cut }\end{array}$ & $\begin{array}{l}q a w^{3} \\
\text { take }\end{array}$ & $\begin{array}{l}\text { khèèn } \\
\text { arm }\end{array}$ & $\begin{array}{l}p a j^{3} \\
\text { go }\end{array}$ & $\begin{array}{l}k h e ̀ e ̀ n \\
\text { arm }\end{array}$ \\
\hline
\end{tabular}

'Someone came and cut one of his arms off.'

While there is a great deal of variation in selection of numeral classifier for many nouns, there are also many nouns denoting familiar/traditional objects (such as teeth, fishing nets, or corn cobs), with respect to which speakers do not vary at all in their selection of numeral classifier.

\subsection{Semantics of numeral classifiers}

A detailed discussion of the semantics of numeral classifiers is beyond the scope of this paper, but a few points may be noted. A significant subset of numeral classifiers refer to distinctions in physical form, including shape and configuration, as illustrated in Table 3:

\begin{tabular}{|c|c|c|c|}
\hline $\begin{array}{l}\text { Shape/form } \\
\text { semantics }\end{array}$ & Examples & & \\
\hline "Zero-dimensional" & $m e ̂ t^{I}$ 'grain, speck' & & \\
\hline "One-dimensional" & sên ${ }^{5}$ 'long thin thing' & $s a a j^{3}$ 'strip, ribbon' & $\begin{array}{l}\operatorname{lam}^{2} \text { 'huge tubular } \\
\text { thing' }\end{array}$ \\
\hline "Two-dimensional" & $b a j^{3}$ 'leaf' & phùùn ${ }^{3}$ 'cloth' & phèèn ${ }^{I}$ 'stiff sheet' \\
\hline $\begin{array}{l}\text { Round "two- } \\
\text { dimensional" }\end{array}$ & duang ${ }^{3}$ 'disk' & vong 'ring' & \\
\hline $\begin{array}{l}\text { "Three- } \\
\text { dimensional" }\end{array}$ & nuaj 'unit, fruit' & & \\
\hline Shape and origin & tòòn ${ }^{I}$ 'hewn chunk' & $\begin{array}{l}\text { kòòn }{ }^{4} \text { 'formed } \\
\text { chunk' }\end{array}$ & $\begin{array}{l}\text { piang' 'cut chunk/ } \\
\text { slice' }\end{array}$ \\
\hline Configuration & $k o ̀ \dot{o}^{3}$ 'clump' & kòòng 'heap' & $k o ̀ o^{4}$ 'coil' \\
\hline Handleability & $q^{2} n^{3}$ 'small thing' & & \\
\hline
\end{tabular}

Table 3: Some shape/configuration distinctions made by numeral classifiers in Lao

Other numeral classifiers do not make semantic distinctions in shape/form. Some refer to "taxonomic essence", such as maak ${ }^{5}$ 'fruit', a numeral classifier which can be used for counting fruits. More commonly, however, fruits are counted using nuaj ${ }^{1}$ 'unit', the general numeral classifier for round things. Some classifiers refer to interactional/functional features of objects, such as khan 'handle' for vehicles and umbrellas, all of which are 'operated by hand'. Note, however, that not all hand-operated items are counted using khan'. Knives, for example, are not. Honorific meaning is expressed by at least one numeral classifier, namely qong $^{3}$, used for counting monks. Finally, note that many numeral classifiers have conventional applications which are not predicted by their basic productive semantics. For example, duang ${ }^{3}$, a classifier used for flat disc-like things (such as the moon), is often used for counting knives. (A common shape-based alternative is $q a n^{3}$.) 


\subsection{Mensural terms in the numeral classifier construction}

A common use of the numeral classifier construction delineates countable amounts of a mass referent by specifying a unit of measure in the numeral classifier slot. Table 4 lists some of these "mensural classifiers":

\begin{tabular}{|l|l|l|}
\hline “Classifier” & $\begin{array}{l}\text { Meaning as } \\
\text { noun (or verb) }\end{array}$ & Example referents \\
\hline$m a t^{I}$ & 'tie' (n./v.) & anything that can be bunched by tying \\
\hline$k a m^{3}$ & 'handful' (n./v.) & anything that can be measured in handfuls \\
\hline$k \dot{o} \dot{o}^{4}$ & 'coil' (n./v.) & anything that can be coiled \\
\hline$k h u u^{I}$ & 'pair' & candles, shoes, couples \\
\hline toon $^{3}$ & 'ton' & any weighable mass \\
\hline loo $^{2}$ & 'kilogram' & any weighable mass \\
\hline
\end{tabular}

Table 4: Some "mensural classifiers"

The following example shows three different "mensural classifiers" being used with reference to a single noun, vaj $^{3}$ 'rattan':

\begin{tabular}{|c|c|c|c|}
\hline (20) & $\begin{array}{l}k h \grave{o ̀ j}{ }^{5} \\
\text { 1sG }\end{array}$ & $\begin{array}{l}\operatorname{sùǘ}^{4} \\
\text { buyy }\end{array}$ & $\begin{array}{l}v_{a a j}^{3} \\
\text { rattan }\end{array}$ \\
\hline
\end{tabular}

'I bought two coils/ties/tons of rattan.'

The choice of mensural classifier in (20) reflects differences in the gauge and amount of rattan purchased.

"Mensural classifiers" clearly do not "classify" in the sense of categorizing the main noun primarily in terms of inherent properties of shape/form. Nevertheless, they do convey certain information about the physical nature of the referent. Clearly, something that can be counted in "ties" must have certain physical properties and dimensions which make it "tie-able". Mensural classifiers generally display grammatical properties of numeral classifiers.

\subsection{A construction for focusing on the shape/form semantics of numeral classifiers}

There is a special adverbial construction in Lao in which a copula verb pên 'be' takes a nominal complement which describes the shape or form of one of the core arguments of the clause. The following examples show the nouns $m o{ }^{3}{ }^{3}$ 'doctor' and $\mathrm{kaj}^{l}$ 'chicken' in optional adjuncts hosted by $p \hat{e} n^{3}$ 'be', predicating the role and physical manifestation, respectively, of the subject of the main clause:

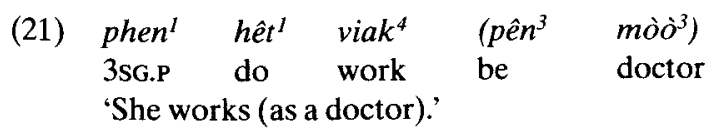




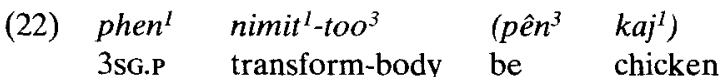

'S/he transformed him-/herself (into chickens/a chicken).'

Neither of the complements of $p \hat{e} n^{3}$ 'be' in these two examples - neither mò $\partial^{3}$ 'doctor' nor $k a j^{I}$ 'chicken' - are classifiers.

Since numeral classifiers often have meanings which denote general shape and/or form of a thing, they may often appear as the complement of $p \hat{e} n^{3}$ 'be' in this construction. Compare the following two examples involving salii 'corn', where one example involves a numeral classifier denoting shape/form, while the second involves a mensural term denoting units of weight:

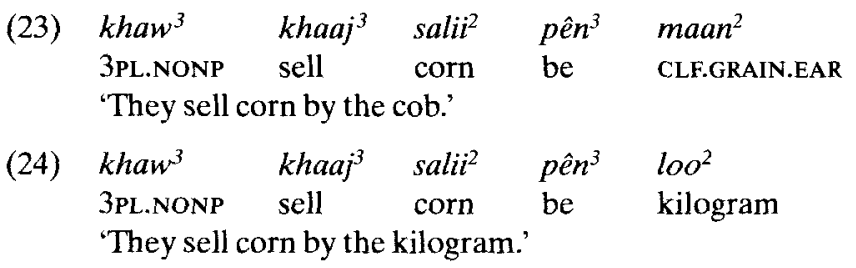

If the nominal complement of $p \hat{e} n^{3}$ 'be' is a numeral classifier, the 'pên ${ }^{3}$ CLF' adjunct often has a depictive meaning 'whole' (ENFIELD forthcoming). The following example, from a mythical tale, illustrates with nuaj $^{1}$, the numeral classifier for mountains (among other things):

\begin{tabular}{|c|c|c|c|c|c|}
\hline (25) & $\begin{array}{l}\operatorname{man}^{2} \\
\text { 3SG.NONP }\end{array}$ & $\begin{array}{l}\text { hò } p^{5} \\
\text { carry.in.both.arms }\end{array}$ & $\begin{array}{l}\text { phuu }{ }^{2} \\
\text { mountain }\end{array}$ & $\begin{array}{l}p e ̂ n^{3} \\
\text { be }\end{array}$ & $\begin{array}{l}\text { nuaj }^{l} \\
\text { CLF.UNIT }\end{array}$ \\
\hline
\end{tabular}

Repeater classifiers cannot be used in this construction, nor can classifiers restricted to modifier classifier environments, such as $p h u u^{5}$ 'person'.

The copula pên 'be' can also take a nominal complement in simple statements about the shape/form of something. In the following two examples, the first shows a regular noun denoting substance ( $\mathrm{maj}^{4}$ 'wood') as the nominal complement of $p e n^{3}$ 'be', while in the second and third examples the complement of $p e n^{3}$ 'be' is a numeral classifier referring to shape/form:
(26) $\operatorname{man}^{2} \quad p \hat{e} n^{3} \quad m a j^{4}$
3sG be wood
'It's (made of) wood.'
(27) $\operatorname{man}^{2} \quad p e n^{3} \quad$ phè̀n ${ }^{1}$
3sG be CLF.STIFF.SHEET
'It's a stiff sheet-shaped thing.'
(28) $\operatorname{man}^{2} \quad \tilde{n} a n g^{2} \quad p e n^{3} \quad t^{4} n^{4} \quad j u u^{I}$

3SG still be CLF.PLANT PCL

'It's still in the form of a plant/tree (e.g. it hasn't yet been shredded).'

Other nominal complements of $p e n^{3}$ 'be' do not express shape/form or physical substance, but rather role or identity (cf. also examples (21) and (22), above): 


\section{(29) phen $^{1}$ pên ${ }^{3} \quad k h u u^{2} /$ thahaan $^{3} /$ khon $^{2}$-latsia ${ }^{2}$ \\ 3sG.P be teacher/soldier/CT.PERSON-Russia \\ 'S/he is a teacher/soldier/Russian.'}

\subsection{A construction in which the numeral classifier alone conveys the meaning 'one'}

In a construction meaning 'one more (NP)', a numeral classifier alone can stand for 'one' (i.e. no numeral need be explicitly expressed).

The word qiik ${ }^{5}$ 'more' can appear with an adverbial meaning after a verb phrase, as in the following example:

$\begin{array}{lllll}\text { (30) } k u u^{3} & s^{0} \quad \mathrm{kin}^{3} & \mathrm{paa}^{3} & q \ddot{i i k} k^{5} \\ & \text { 1sG.NONP IRR eat fish } & \text { more } \\ \text { 'I'm going to eat more fish.' } & & \end{array}$

It may also take as a complement a numeral classifier construction which enumerates the object argument:
(31) $k u u^{3}$ $s i^{0} \quad \mathrm{kin}^{3}$
$p a a^{3}$
qiik ${ }^{5}$
sò̀ng ${ }^{3}$
$\operatorname{too}^{3}$
1sG.NONP IRR eat fish
more two CLF.ANIM
'I'm going to eat another two fish.'

In case the numeral to be expressed is 'one', it is possible to use nùng 'one' as it normally would be used in a numeral classifier construction (either immediately before or immediately after the numeral classifier), but it is also possible, and indeed common, to omit the numeral altogether, in which case the combination of $q i k^{5}$ 'more' with the bare numeral classifier expresses the notion 'one more', with the numeral 'one' not explicitly expressed:

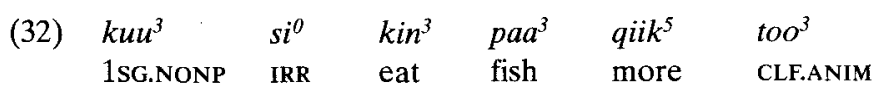
'I'm going to eat another fish.' (NOT: 'I'm going to eat more fish.')

It is possible to use repeaters, part/whole type and/or mensural classifiers in this construction, as the following examples demonstrate:
(33) lêp ${ }^{1}$

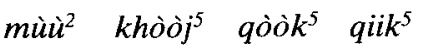
lêp $p^{1 / q a n^{3} / \text { diw }^{4}}$
nail/claw hand 1sG.P exit more nail/CLF.SMALL.THING/CLF.FINGER
'Another one of my fingernails has come off.'
(34) $k_{u u^{3}} \quad \mathrm{si}^{0} \quad \mathrm{kin}^{3} \quad \mathrm{paa}^{3} \quad q u i k^{5} \quad l o o^{2}$
1SG.NONP IRR eat fish more CLF.KILOGRAM

'I'm going to eat another kilo of fish.'

\subsection{Speaker awareness of numeral classifiers}

Numeral classifiers enjoy a high level of conscious speaker awareness, being an occasional topic for discussion among speakers, and being the focus of both official and unofficial normative conventions (cf. JunTanamalaga 1988 on Thai). Speakers freely discuss which classifier is considered correct for counting which noun. It is not surprising that speakers are apt to reflect consciously on these morphosyntactic items, given their salience both in the phonology (appearing in phrase-final position, stressed), and in the discourse (being typically used in association with definite referents whose quantification and shape/ 
function properties are in focus). Their cultural importance stems not only from their association with material artefacts, but also with the social significance of knowing "the right classifier" to use in a given instance. However, informal observations reveal that while speakers' intuitions about the meaning and distribution of classifiers in numeral classifier contexts are more or less sound, the differences between speakers' choices of classifiers with particular nouns in numeral classifier and modifier classifier contexts (see next section) seem beyond the level of awareness. That is, while a speaker may identify a certain classifier as "the right one" to be used with a certain noun, they will be unaware that in modifier classifier contexts (in which there is less discourse focus on the function of the classifier, as well as a much weaker phonological realization), they do not use that classifier, but switch to something semantically very general.

\section{Modifier classifiers}

Modifier classifiers are used in the expression of various nominal modifiers, including the demonstrative determiners $n i i^{4}$ 'this' and $n a n^{4}$ 'that', the quantifier nùng ' 'one', relative clauses, and adjectives. There does not seem to be any restriction on their use with any semantic sub-types of adjectives. In principle, any numeral classifier (including repeaters and mensural classifiers) can appear in a modifier classifier function, but in practice many distinctions are neutralized, with only a small number of numeral classifiers being used in these contexts. Importantly, the grammatical position of the classifier in these uses is different from that of the numeral classifiers, and it results in a significant phonological distinction between the two classifier functions. The most common classifiers used - $t o o^{3}$ 'body' and qan $^{3}$ 'small thing' - have different meanings in the modifier classifier contexts and the numeral classifier contexts. In modifier classifier contexts, they can be used for almost any noun, whereas their applicability is significantly restricted in the numeral classifier context (including the constructions discussed in $\$ 2.2, \S 2.6$, and $\$ 2.7$, above). Further, there is at least one classifier ( $p h u u^{5}$ 'person') which is used exclusively in the modifier classifier context, and cannot be used as a numeral classifier.

Numeral classifier constructions discussed in the previous section are unusual in the context of the typological structure of Lao in that the order of classifier and modifying element - with the numeral preceding the classifier - is the opposite of the almost exclusively head-initial pattern of Lao noun phrases. The following examples show that the combination of noun or classifier with numeral (example (35)) patterns oppositely to the combination of noun or classifier with attributive modification (e.g. adjectives, demonstratives, and relative clauses; examples (36-38)). The head of the noun phrase in each case is $k h o n^{2}$ 'person/people', given in boldface:

$$
\begin{aligned}
& \text { sò̀ng } \boldsymbol{k h h o n}^{2} \\
& \text { two person } \\
& \text { 'two people' }
\end{aligned}
$$

(36) khon ${ }^{2}$ suung ${ }^{3}$ person tall 'tall person'

(37) $\boldsymbol{k h o n}^{2}$ niï/qùùn person DEM.GEN/other 'this/another person' 


$$
\begin{aligned}
& \boldsymbol{k h o n}^{2} \quad \text { thii }^{I} \text { caw }^{4} \quad h e n^{3} \\
& \text { person REL 2SG.P see } \\
& \text { 'the person who you saw' }
\end{aligned}
$$

An important consequence of this difference in head-modifier ordering for numeral classifier versus modifier classifier contexts concerns stress patterns of Lao words. Nonmonosyllabic Lao words and phrases are stress-final, resulting in pre-final elements becoming reduced. Many monomorphemic lexical items, for example, have sesquisyllabic (one-and-a-half-syllable) structure, in which a primary syllable (i.e. with full stress and with expression of the full range of contrasts in vowel length and lexical tone) is preceded by a reduced "half syllable" (with highly restricted phonotactic possibilities, and no contrast in vowel length or tone). For example, the word kabuang 4 'ceramic tile' features a pre-syllable $k a$ - (unstressed, without contrastive tone or vowel length) and a primary syllable -bùang ${ }^{4}$ (stressed, with long complex vowel and contrastive lexical tone). (This word contrasts with, for example, bùang ${ }^{4}$ 'side' and kabong 'caterpillar'.) This pattern also applies to polymorphemic words or phrases, and this stress-final word/phrase structure affects the phonological realization of certain morphemes taking different roles as grammatical components in phrasal combinations.

An illustrative example concerns the classifier for non-human animates, which surfaces as $t^{3} o^{3}$ when in a numeral classifier position (with the modifier coming before it, as in example (39)), but as unstressed $t o^{O}$ when in a modifier classifier position (with the modifier coming after it, as in examples (40) and (41)). Note the different patterns of stress in these examples (primary and secondary stress are marked by " 'and ", respectively; the classifier is given in boldface):

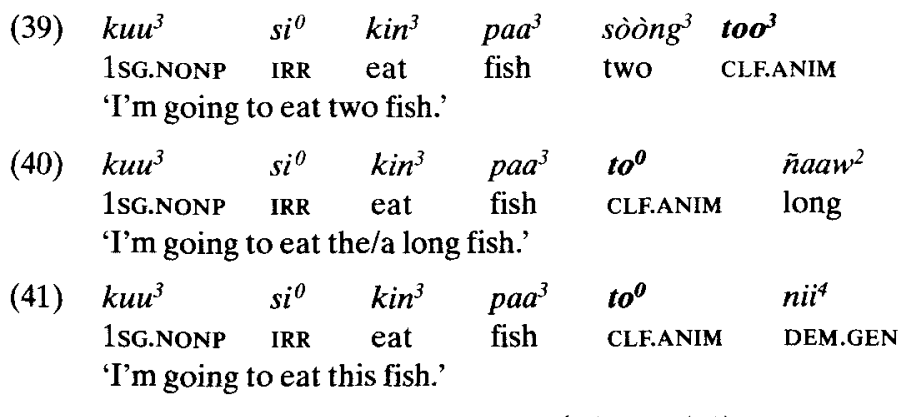

Demonstrative determiners such as $n i i i^{4}$ 'this' in (41) cannot appear as independent noun phrases:

(42) $* k u u^{3} \quad s i^{0} \quad \mathrm{kin}^{3} \quad \mathrm{nii}^{4}$

1SG.NONP IRR eat DEM.GEN

(I'm going to eat this.)

However, the main noun in (41) may be ellipsed, as follows:

$\begin{array}{llllll}\text { (43) } & k u u^{3} & s^{0} & k^{2} n^{3} & t o^{0} & n i i^{4} \\ & \text { 1sG.NONP IRR eat } & \text { CLF.ANIM } & \text { DEM.GEN } \\ & \text { 'I'm going to eat this one.' } & & \end{array}$

If both a numeral and a modifier such as a demonstrative or adjective are to be used in the same phrase, the modifier classifier pattern is used: 


$\begin{array}{lllllll}k u u^{3} & \mathrm{si}^{\circ} & \mathrm{kin}^{3} & \mathrm{paa}^{3} & \text { sòòng } & \text { to } & n i i^{4} \\ \text { 1sG.NONP } & \text { IRR } & \text { eat } & \text { fish } & \text { two } & \text { CLF.ANIM } & \text { DEM.GEN }\end{array}$

'I'm going to eat these two fish.'

De-stressing of the modifier classifier in pre-nominal position is most apparent in the cases of the two classifiers of most general meaning, too $^{3}$ 'body' and qan ${ }^{3}$ 'small thing'. Phonological reduction of a number of other classifiers in this environment is significantly less noticeable due to their greater phonological weight. An example is phùùn ${ }^{3}$ (a classifier for cloths and similar objects):

(45)

$k h \grave{o ̀ j} j^{5} \quad s \grave{u} \grave{u}^{4} \quad \sin ^{5}$ 'I bought two skirts.'

$\begin{array}{lllll}\text { khòj }^{5} \quad \operatorname{mak}^{l} & \sin ^{5} & \text { phùùn } & n i^{4} \\ \text { 1sG.P like } & \text { Lao.skirt } & \text { CLF.CLOTH } & \text { DEM.GEN } \\ \text { 'I like this skirt.' } & & & \end{array}$

The modifier classifier context is one in which the very large number of semantic distinctions among numeral classifiers is often neutralized. It is often the case that a conventionally assigned numeral classifier is replaced in this context with either of the two more general classifiers $t^{3} o^{3}$ 'body' or qan $^{3}$ 'small thing', phonologically reduced accordingly. The following are perfectly idiomatic alternatives for (46):

\begin{tabular}{|c|c|c|c|c|}
\hline khòoj ${ }^{5}$ & $m a k^{l}$ & $\sin ^{5}$ & $t o^{0}$ & $n i i^{4}$ \\
\hline 1sG.P & like & Lao.skirt & CLF.ANIM & DEM.GEN \\
\hline \multicolumn{5}{|c|}{ 'I like this skirt.' } \\
\hline$k h o ̀ o j j^{5}$ & $m a k^{1}$ & $\sin ^{5}$ & $q a n^{\theta}$ & $n i i^{4}$ \\
\hline 1SG.P & like & Lao.skirt & CLF.SMALL.THING & DEM.GEN \\
\hline
\end{tabular}

Numeral classifiers of greater semantic specificity tend not to be used as modifier classifiers. This is clearly related to the functional status of these uses. In example (47), where the classifier is structurally hosting a demonstrative, specific information concerning shape and/or form is unnecessary for the basic task of picking up reference to something already active in the discourse or present in the speech situation. Indeed, this makes selection of a more semantically specific classifier in a modifier classifier context pragmatically marked (compare examples (46) and (47)). The classifiers too ${ }^{3}$ 'body' and $q a n^{3}$ 'small thing', which in numeral classifier contexts are restricted in their application by semantic specificity, clearly have more generalized meanings in modifier contexts, being used with a greater range of nouns than is possible in numeral classifier contexts (cf. CARPENTER 1986 for the same phenomenon in Thai). This shows that these two classifiers in their numeral classifier and modifier classifier roles are actually distinct lexical items, with distinct meanings and functions.

\subsection{A special modifier classifier for people - phuu $^{5}$}

The distinction between numeral classifiers (in CLF-NUMERAL order) and modifier classifiers (in MODIFIER-CLF order) is reflected in the existence of a special modifier classifier for people, lexically distinct from the numeral classifier used for people. The nominal element 
$p h u u^{5}$ 'person' never occurs as an independent noun and can only occur in a prenominal modifier classifier slot, and thus never takes primary stress (cf. examples 36-38, above):

\begin{tabular}{|c|c|c|c|}
\hline (49) & $\begin{array}{l}\left(m \dot{o} \dot{o}^{3}\right) \\
\text { doctor } \\
\text { 'this one }\end{array}$ & $\begin{array}{l}\text { phu } \\
\text { CLF.HUM } \\
\text { ctor)' }\end{array}$ & $\begin{array}{l}n i i^{4} \\
\text { DEM.GEN }\end{array}$ \\
\hline (50) & $\begin{array}{l}\left(m \grave{o} \dot{o}^{3}\right) \\
\text { doctor } \\
\text { 'the tall }\end{array}$ & $\begin{array}{l}\text { phu } \\
\text { CLF.HUM } \\
\text { (doctor)' }\end{array}$ & $\begin{array}{l}\text { suung } \\
\text { tall }\end{array}$ \\
\hline (51) & $\begin{array}{l}\left(m \grave{o} \grave{o}^{3}\right) \\
\text { doctor }\end{array}$ & $\begin{array}{l}p h u^{\circ} \\
\text { CLF.HUM }\end{array}$ & $\begin{array}{l}c a w^{4} \\
2 \text { SG.P }\end{array}$ \\
\hline
\end{tabular}

In a numeral classifier construction where the numeral classifier comes after the specifier, only $k h o n^{2}$, and not $p h u u^{5}$, can be used:

\begin{tabular}{|c|c|c|c|}
\hline (52) & $\begin{array}{l}m \dot{o} \grave{o}^{3} \\
\text { doctor } \\
\text { 'two doctors' }\end{array}$ & $\begin{array}{l}\text { sòòng } \\
\text { two }\end{array}$ & $\begin{array}{l}\text { khon }^{2} \\
\text { CLF.HUM }\end{array}$ \\
\hline$(60)$ & $\begin{array}{l}{ }^{*} m \grave{o} \grave{o}^{3} \\
\text { doctor } \\
\text { (two doctors) }\end{array}$ & $\begin{array}{l}\text { sòòng } \\
\text { two }\end{array}$ & $\begin{array}{l}p h u u^{5} \\
\text { CLF.HUM }\end{array}$ \\
\hline
\end{tabular}

There is no lexical distinction analogous to that of $k h o n^{2}$ versus $p h u u^{5}$ which explicitly reflects a differentiation between numeral classifiers and modifier classifiers in the domain of non-human referents.

\subsection{Nominal modification}

As already noted, modifier classifiers can be used with any kind of nominal modification. With some kinds of modifiers, such as demonstrative determiners, they are obligatory (see example (42), above). In expressions involving modification of a noun by an adjective or relative clause (hardly distinct categories in Lao), classifiers may be used, but are not obligatory. The next example shows $t o o^{3}$ 'body' hosting a relative clause modifying $p^{3} a^{3}$ 'fish' (see also examples (36-38) and (50-51), above):

$\begin{array}{llllll}\text { (54) } k h o ̀ j j^{5} & \mathrm{kin}^{3} & \mathrm{paa}^{3} & \text { too }^{3} & \mathrm{caw}^{4} & \text { sùŭ }^{4} \\ \text { 1sG.P } & \text { eat } & \text { fish } & \text { CLF.ANIM } & \text { 2sG.P } & \text { buy }\end{array}$

'I ate the fish (the one which) you bought.'

It is also possible to use the dedicated relativizer $t h i^{l}$, or no marker at all:

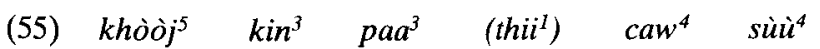
1sG.P eat fish REL 2sG.P buy 'I ate the fish (which) you bought.'

Without further information, I am unable to identify any precise meaning difference between (54) and (55), beyond what I have attempted to convey with the English translations. 
HundIUS \& KöLVER (1983:172) hypothesize that in Thai, the choice as to whether or not to omit the classifier in examples such as $(54)$ has consequences on interpretation. ${ }^{6}$ Specifically, if the classifier is included, the reading will almost always be understood as singular (whereas it is non-determinate in number if no classifier is supplied). Furthermore, say HundIUS \& KöLVER (1983: 173), "it implies either definite reference, or else a contrastive referential value of the adjective". The same is the case in Lao. (See § 3.3, below, for further discussion of this "unitizing" function.)

There are further cases in which more than one classifier phrase features in a complex noun phrase, "stacked up", modifying a single noun (cf. HundIUs \& KölvER 1983: 172-177 on Thai). Consider the following example:

$$
\begin{array}{llllllll}
\text { phen }^{I} & \mathrm{kin}^{3} & \mathrm{paa}^{3} & t o^{0} & \tilde{n} a a w^{2} & t o^{0} & \mathrm{caw}^{4} & \operatorname{sù~}^{4} \\
\text { 3sG.P } & \text { eat } & \text { fish } & \text { CLF.ANIM } & \text { long } & \text { CLF.ANIM } & \text { 2sG.P } & \text { buy }
\end{array}
$$

'S/he ate the fish, the long one, the one you bought.' (cf.: 'S/he ate the long fish you bought.')

This may be analyzed as a series of distinct nominal phrases in apposition, each headed by a classifier, and each elaborating semantically on the main noun, which is a distinct noun phrase (as reflected in the first English translation given). In favor of this analysis, it is possible to insert an adjunct or sentence-final particle between the main noun and a classifierplus-modifier phrase, showing that the modifier is an independent constituent (cf. example (2), above).

Here is another example, from a text recording, in which the main noun luuk ${ }^{4}$ 'child' takes three modifiers (a demonstrative and two adjective/relative clauses), each hosted by a separate instance of the modifier classifier phuu $u^{5}$ 'person' (realized as unstressed $p h u^{0}$ ):

\begin{tabular}{|c|c|c|c|c|c|c|c|}
\hline phòò ${ }^{I}-m e ̀ e^{l}$ & $k a^{0}$ & $b \grave{o}^{0}$ & ñòm & $p a j^{3}$ & nam $^{2}$ & $l u u k^{4}$ & $p h u^{0}$ \\
\hline & FOC.PCL & NEG & yield & go & with & child & CLF.PERSON \\
\hline$n a n^{4}$ & $p h u^{o}$ & & hang ${ }^{1}$ & $p h u^{o}$ & $m i i^{2}$ & & \\
\hline DEM.NONPROX & CLF.PERS & & rich & CLF.PERSON & have & PCL & \\
\hline
\end{tabular}

'The parents won't go with that rich, wealthy child.'

(i.e. 'The parents won't go with child, that one, the rich one, the wealthy one.')

\subsection{A "unitizing" function}

Two cases described above - a construction "more CLF" having the meaning "one more" ( $\$ 2.7$.), and the use of classifiers in nominal modification implying singularity/definiteness of the referent ( $\$ 3.2$.) - suggest a "unitizing" function of classifiers. Here is another case, a subtle use of modifier classifiers in which the classifier appears by itself in combination with a main noun, where no modifier of the main noun is involved (cf. noun classifiers in Australian and Mayan languages; AikHenvald 2000: Chapter 3, Grinevald 2000: 64-65). Compare the following two sentences:

- Lao and Thai show extensive grammatical similarity, being close enough in structure to be treated as dialects. (But Thai is not "a dialect of Lao", just as Lao is not "a dialect of Thai".) While they do show some important differences, a claim about the general typological structure of one can usually be treated as a claim about the other. This is certainly true with regard to systems of nominal classification. 


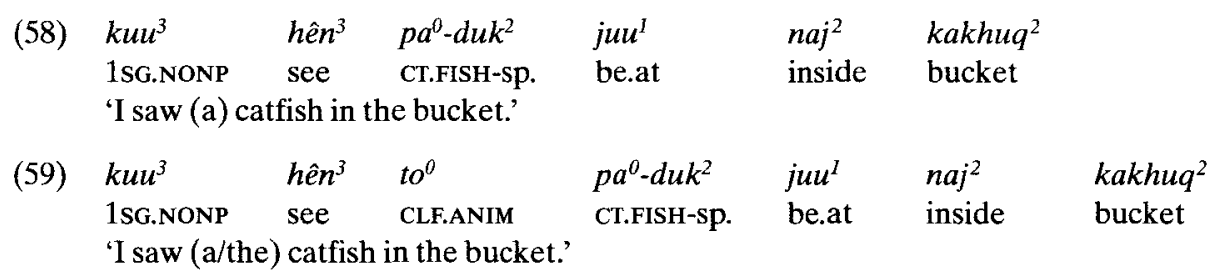

In the second example, the nominal $p a^{o}$-duk ${ }^{2}$ 'catfish' is preceded by $t o o^{3}$ 'body' (destressed, thus appearing as $\left.t o^{o}\right)$, the numeral classifier used for fish. The meaning difference between the two examples is subtle. The presence of the classifier in (59) suggests "unitization", implying (but not entailing) that there is just one fish being referred to. The absence of the classifier in (58) gives rise to no particular expectation regarding the number of fish being referred to. Further, as suggested for Thai by Hundius \& KöLVER (1983) regarding the presence of a classifier in noun-modifying phrases, there is a greater likelihood that the referent in (59) is definite. Further work is required to demonstrate and elucidate this.

The next two examples show the same pattern of alternation, with optional use of the classifier $n u a j^{l}$ '(assembled) unit' appearing immediately before the main noun toq ${ }^{2}$ 'table':

(60)

$\begin{array}{llllll}k u u^{3} & h e n^{3} & t o q^{2} & j u u^{I} & n a j^{2} & h o ̀ o n g^{5} \\ \text { 1sG.NONP } & \text { see } & \text { table } & \text { be.at } & \text { inside } & \text { room }\end{array}$

'I saw (a) table(s) in the room.'

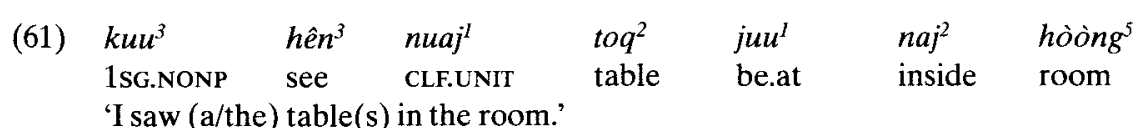

Again, the second example, with the classifier alone forming a phrase with the main noun, suggests that there is just one table, while the first implies nothing about number. Also, a "definite" reading is more likely in the second example.

Classifiers which can perform this function are generally restricted to those which explicitly refer to shape or form. The following examples show that this function cannot be performed by classifiers which do not pick out their referents in terms of shape/form specification (either because the shape/form specifications of the referent do not match those of its conventional classifier - as in $h u a^{3}$ 'head/bulb' for books - or the classifier simply has no shape/form information - as in $k h a n^{2}$ for vehicles):

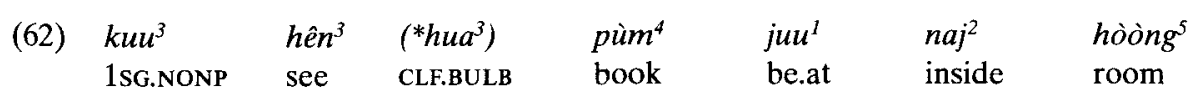

'I saw (a) book(s) in the room.'

(63) $k u u^{3} \quad h e n^{3}\left({ }^{*} k h a n^{2}\right) \quad l o t^{0}-c a k^{2} \quad j u u^{l} n a j^{2} h \grave{o o ̀ n g}{ }^{5}$ 1SG.NONP see CLF.VEHICLE CT.VEHICLE-motorcycle be.at inside room 'I saw (a) motorcycle in the room.'

It is possible to use phuu 'person' (but not the corresponding numeral classifier khon ${ }^{2}$ 'person') in this context, with the connotation that the referent person is a familiar/ recognizable individual: 


\begin{tabular}{|c|c|c|c|c|c|c|c|}
\hline (64) & $\begin{array}{l}k u u^{3} \\
\text { 1sG.NONP }\end{array}$ & $\begin{array}{l}h e \hat{n}{ }^{3} \\
\text { see }\end{array}$ & $\begin{array}{l}p h u^{o} \\
\text { CLF.PERSON }\end{array}$ & $\begin{array}{l}\text { qaaj }^{4} \\
\text { older.brother }\end{array}$ & $\begin{array}{l}\operatorname{man}^{2} \\
\text { 3sG.NONP }\end{array}$ & $\begin{array}{l}j u u^{l} \\
\text { be.at }\end{array}$ & $\begin{array}{l}\text { talaat }^{5} \\
\text { market }\end{array}$ \\
\hline
\end{tabular}

As in other modifier classifier functions, the classifier is the head of the phrase in these "unitizing" functions. The difference here is that the element dependent on the classifier is the main noun itself.

\section{Class terms}

Lao has a dozen or so of morphemes which may occur as independent nouns and which also appear as the initial and more semantically general component of many polymorphemic nouns denoting objects and people. They do not categorise the element to which they attach, but rather the whole compound of which they are a part. In this role they are phonologically dependent and lexically specified (thus obligatory). I refer to them as class terms (GRINEVALD 2000: 59). The set of class terms is not the same as the set of numeral classifiers, but there is partial overlap.

An illustrative example is the use of the word for 'fish' $-p a a^{3}$ - as the initial component in names of individual fish species (KERR 1972: 771ff. lists over a hundred). In this initial position, $\mathrm{paa}^{3}$ 'fish' is reduced to unstressed/atonal $\mathrm{pa}^{0}$, where the (usually monosyllabic) element denoting the species of fish takes lexical stress (according to the phonological structure of words as stress-final, as described above):

(65) $p a^{0}-d u k^{2}$

CT.FISH-Sp.

'catfish'

(66) $p a^{0}-$ thuu $^{2}$

CT.FISH-Sp.

'mackerel'

Sometimes the modifier is semantically transparent, as part of a (sometimes figurative and/or metonymic) description of the fish:

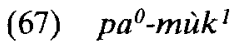

CT.FISH-ink

'ink fish, squid'

(68) $p a^{0}-k h a m^{2}$

CT.FISH-gold

'goldfish'

GRINEVALD (2000: 59) regards class terms as "classifying morphemes" rather than "classifiers". These are distinct from what she identifies as "noun classifiers", which are "free morphemes" not involved with derivation in the lexicon (GRINEvald 2000: 64). By contrast, AikHENVALD's (2000: Chapter 3) definition of "noun classifier" would encompass the Lao class terms described in this section.

We now examine some categories of class terms, based on semantic properties. 


\subsection{Class terms denoting taxonomic "essence"}

The most common and extensive uses of class terms denote taxonomic or biological "essence" of the marked noun. By "essence" I mean the fundamental nature of a thing, usually in terms of higher-level taxonomic kind such as 'fish', 'tree', or 'fruit'. The following table shows some examples:

\begin{tabular}{|c|c|c|}
\hline Class term & Meaning as a noun & Referents \\
\hline$p a^{0}$ & $p_{a a}^{3}$ 'fish' & kinds of fish \\
\hline mèng ${ }^{0}$ & mèèng ${ }^{2}$ 'insect' & kinds of insect \\
\hline$m a k^{0}$ & maak ${ }^{5}$ 'fruit' & kinds of fruit \\
\hline nam $^{0}$ & nam 4 'water' & kinds of liquid \\
\hline$m a j^{O_{-}}$ & $m a j{ }^{4}$ 'wood' & kinds of tree, kinds of wood \\
\hline$k h a w^{0}$ & $k h a w^{5}$ 'rice' & kinds of rice or cereal \\
\hline $\operatorname{man}^{0}$ & $\operatorname{man}^{2}$ 'root vegetable' & kinds of root vegetable \\
\hline
\end{tabular}

Table 5: Some examples of class terms denoting biological "essence"

One class term which does not denote "essence" in a biological sense, but refers more to fundamental physical essence, is $s i i^{3}$ 'color', which appears in compound terms referring to different colors. There are two classes of color terms in Lao, based on grammatical properties, with one group consisting of basic terms (including dèng $3^{3}$ 'red', lùang 'yellow', $k_{h i a w^{3}}$ 'green/blue'), which are grammatically more versatile, and one group consisting of non-basic terms (including $\mathrm{faa}^{4}$ 'blue; sky' and $b u a^{3}$ 'pink/purple; lotus'), which are subject to certain grammatical constraints. One grammatical difference between the two categories, illustrated in the following examples, is that the class term $s i i^{3}$ 'color' is obligatory only with the second "non-basic" category:

(69) lot $^{1} \quad\left(\right.$ sii $\left.^{3}\right)$-dè̀ng ${ }^{3}$

vehicle color-red

'red (colored) car'

(70) $\operatorname{lot}^{1} \quad *\left(s i^{3}\right)-f a a^{4}$

vehicle color-blue

'blue * (colored) car'

\subsection{Class terms denoting occupation/role}

The kinship terms $m \grave{e} \grave{I}^{I}$ 'mother' and phò $\grave{o}^{I}$ 'father' are used derivationally as class terms, denoting male and female occupations, respectively. Here are a few examples of female occupations involving mè̀ ${ }^{I}$ 'mother' as a prefixed and phonologically reduced element: 


\begin{tabular}{|c|c|}
\hline Expression & Meaning of modifier \\
\hline$m \grave{e}^{0}-k h u a^{2}$ 'cook' (f.) & $k h u a^{2}$ 'prepare food for cooking' \\
\hline$m \grave{e}^{0}$-caang ${ }^{4}$ 'prostitute' & caang' 'hire someone's services' \\
\hline$m e^{\circ}-k h a a w^{3}$ 'nun' & khaaw' white'? \\
\hline
\end{tabular}

Table 6: Some examples of female occupation terms headed by 'mother' as a class term

Another word used as a class term in certain occupation terms is naaj ${ }^{2}$ 'boss, lord' (KERR 1972: 702-703 gives many examples):

\begin{tabular}{|l|l|}
\hline Expression & Meaning of modifier \\
\hline$n a j^{0}$-phasaa ${ }^{3}$ 'interpreter' & phasaa ${ }^{3}$ 'language' \\
\hline$n a j^{0}$-daan' 'border official' & daan' 'border' \\
\hline$n a j^{0}-$ ban $^{4}$ 'village chief' & baan $^{4}$ 'village' \\
\hline$n a j^{0}$-thahaan 'military officer' & thahaan ${ }^{3}$ 'soldier' \\
\hline
\end{tabular}

Table 7: Some examples of occupation/role terms headed by 'lord/boss' as a class term

In some cases, $n a j^{0}$ - is optionally added to a noun of occupation/role to express respect

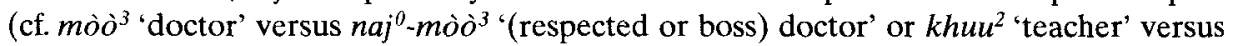
$n a j^{0}-k h u u^{2}$ '(respected or boss) teacher').

A final example differs from the class terms discussed so far, in that it has no independent use as a noun. The "professional" prefix $n a k^{0}$ - (KERR 1972: 694) is a borrowing from Khmer (cf. modern Khmer něak 'person'):

\begin{tabular}{|l|l|}
\hline Expression & Meaning of modifier \\
\hline$n a k^{0}-$ kilaa $^{2}$ 'sportsman' & kilaa $^{2}$ 'sport' \\
\hline$n a k^{0}-$ bin $^{3}$ 'pilot' & bin $^{3}$ 'fly' \\
\hline$n a k^{0}-$ khian $^{3}$ 'writer' & khian $^{3}$ 'write' \\
\hline$n a k^{0}$-qawakaat 'astronaut' & qawakaat 'outer space' \\
\hline
\end{tabular}

Table 8: Some examples of occupation/role terms headed by the "professional" prefix $n a k^{0}$.

\footnotetext{
${ }^{7}$ Buddhist "nuns" in Laos wear white.
} 


\subsection{Class terms denoting function}

Some class terms categorize the compound in terms of function. One productive example involves the word $l o t^{I}$, a general term for any terrestrial vehicle:

\begin{tabular}{|c|c|}
\hline Expression & Meaning of modifier \\
\hline lot -thiip $^{5}$ 'bicycle' & thiip ${ }^{5}$ 'push away with foot' \\
\hline$l o t^{0}-c a k^{2}$ 'motorcycle' & $c a k^{2}$ 'machine' \\
\hline lot ${ }^{0}-k e ̂ n g^{3}$ 'sedan' & kêng ${ }^{3}$ has no independent meaning \\
\hline lot $t^{0}-k u a t^{5}$ 'grader' & $k_{u a t}{ }^{5}$ 'sweep' \\
\hline $\operatorname{lot}^{0}-\operatorname{cok}^{2}$ 'digger' & $\operatorname{cok}^{2}$ 'scoop' \\
\hline $\operatorname{lot}^{0}-\tilde{n} a j^{1}$ 'truck' & $\tilde{n} a j^{l}$ 'big' \\
\hline
\end{tabular}

Table 9: Some examples of 'vehicle' nouns headed by $l o t^{I}$ 'vehicle' as a class term

The lexically derivational role of the class terms should be clear from these examples.

\subsection{A productive class term prefix with cross-categorial applicability: $\mathrm{khii}^{5}$ 'shit'}

A large set of nouns begin with $k h i^{0^{-}}$, a reduced form of $k h i i^{5}$ 'shit'. Unlike other class terms, this word has verb as well as noun uses in other contexts. One class of derived nouns refers to things or substances regarded as by-product, waste or pollutant:

(71a) $k h i^{0}$-dang 'snot' (dang ${ }^{3}=$ 'nose')

(71b) $k h i^{0}$-lùaj ${ }^{1}$ 'sawdust' (lùaj ${ }^{l}=$ 'saw')

(71c) $k h i^{0}$-miang 'rust' (miang' has no independent meaning)

Another category of nouns denotes different kinds of people with negative character traits:

(72a) $k h i^{0}-l a k^{1}$ 'thief' (lak ${ }^{1}=$ 'to steal')

(72b) $k h i^{0}$-tuaq ${ }^{2}$ 'liar' (tuaq ${ }^{2}=$ 'to lie')

(72c) khi ${ }^{0}$-koong 'cheat' (koong ${ }^{3}=$ 'to cheat')

Also unlike other class terms, this prefix is also used to derive verbs (again with meanings referring to negative characteristics):

(73a) $k h i^{0}$-thii 'stingy' (thii ${ }^{1}=$ 'spaced closely together')

(73b) $k h i^{0}-k h u j^{2}$ 'snobby' $\left(k h u j^{2}=\right.$ 'chat')

(73c) $k h i^{0}-k h a a n^{4}$ 'lazy' (khaan' has no independent meaning)

\subsection{The "opaque prefix" ka-}

Hundreds of nouns in the Lao lexicon feature a half-syllable "opaque prefix" $k a$ - (KeRR 1972: 1 calls it "a common untranslatable prefix"). It is a "prefix" in that it is paradigmatically related, at least to some extent, to the class terms described so far in this section; it is "opaque" in that it has no recognizable independent meaning. Even so, there are some 
semantic themes in common among groups of nouns with the $\mathrm{ka}$ - "prefix". Many (but not all) of these terms refer to small creatures (e.g. kataaj' 'rabbit', kabong 4 'caterpillar') or small common domestic artefacts ( $\mathrm{kadum}^{3}$ 'button', $\mathrm{kataa}^{l}$ 'basket').

Four formal categories of nouns can be defined with respect to the pre-syllable $k a$ :

i. Words in which $k a$ - is obligatory:

kadaan $^{3}$ 'board' (daan ${ }^{3}$ is not a word)

$k a h o \partial k^{4}$ 'squirrel' ( $h \grave{o} o k^{4}$ is not a word)

ii. Words in which $k a$ - is optional, with no difference in meaning:

kakhuq' 'bucket' (= khuq ' 'bucket')

kapiing 'leech' (= piing ' 'leech')

iii. Words in which $k a$ - is optional, with a (related but) different meaning:

kapaw $^{3}$ 'bag, case' ( $\neq$ paw $^{3}$ 'sack')

kaloong ${ }^{1}$ 'chest' ( $\neq$ loongl 'coffin')

iv. Words which are semantically appropriate (e.g. denoting small creatures and small common artefacts) yet in which $k a$ - cannot occur:

tangl 'chair' ( $k$ atangl is not a word)

$k o p^{2}$ 'frog sp.' (kakop ${ }^{2}$ is not a word)

The set of nouns beginning with the "opaque prefix" $k a$ - is very large (numbering in hundreds), and while there is no productive or identifiable role for $k a$-in synchrony, its presence in the modern language clearly has historical explanations. The $k a$ - prefix in modern words comes from a range of different historical sources, including possibly ProtoTai, early semantic classes in Proto-Southwestern Tai (possibly due to an Austroasiatic substratum), and borrowing from Mon-Khmer languages (ANTHONy Diller, p.c; cf. Photchani 1993). ${ }^{8}$ In some cases, the prefix $k a$ - may have been applied to native monosyllabic words (having been first abstracted as a "prefix" from borrowed words). ${ }^{9}$

\section{Kin prefixes: kinship and other human references in terms of address}

One type of classificatory "prefix" differs from the types of nominal classification discussed so far, in being neither obligatory nor lexically derivational. These are kinship terms

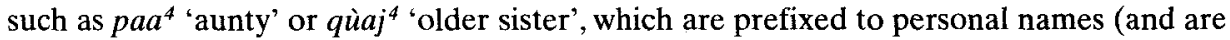
phonologically dependent in these contexts, being de-stressed accordingly), expressing relational meanings of (classificatory) kinship between the speaker and the referent. Here are some examples:

8 See SAGarT (2001: 133-134) for a description of the "not uncommon" phenomenon of "nouns prefixed with $k V \cdot$ " in modern Sinitic languages. These are "always, or almost always, concrete nouns (as opposed to abstract nouns) and count nouns (as opposed to mass nouns)".

9 Speakers certainly recognise that $\mathbf{k a}$-is somehow an independent element (as one would expect given that it is optional in some cases; $\mathrm{cf}$. ii. above), but they cannot characterise its meaning. It is revealing that when pressed, a number of bilingual speakers have compared it to the definite article the in English. 


\begin{tabular}{|c|c|c|}
\hline "Prefix" & Meaning elsewhere & Example referents \\
\hline$p a^{0}$ & $p a a^{4}$ 'aunty' & $p a^{0}$-sèèng ${ }^{3}$ 'Aunty Sèèng' \\
\hline$t u^{0}$ & $t u u^{4}$ 'grandparent' & $t u^{0}$-sèèng ${ }^{3}$ 'Grandma Sèèng' \\
\hline$q a j^{0}$ & $q a a j^{4}$ 'older brother' & $\begin{array}{l}q a j^{0} \text {-sèèng }{ }^{3} \text { 'Sèèng (respected older male of } \\
\text { same generation as oneself)' }\end{array}$ \\
\hline$q \grave{u} a j^{4}-$ & qùaj 'older sister' & $\begin{array}{l}q \grave{u} a j^{0} \text {-sèèng 'Sèèng (respected older female } \\
\text { of same generation as oneself)' }\end{array}$ \\
\hline
\end{tabular}

Table 10: Kinship terms used as classifying prefixes in terms of address

These can be used as modifier classifiers (74), but not as numeral classifiers (75):

(74) $k u u^{3} \quad h e n^{3} \quad q a j^{0} \quad \operatorname{nan}^{4}$

1SG.NONP see older.brother DEM.NONPROX

'I saw him [=that older respected male of same generation].'

(75) *kuu ${ }^{3} \quad h e \hat{n} n^{3} \quad$ sòòng ${ }^{3} \quad q a a j^{4}$

1SG.NONP see two older.brother

(I saw two [=older respected males of same generation].)

Only a subset of kinship terms can be used in this way, namely those that refer to kin "above" (i.e. older than) oneself. Reference to anyone in one's kinship or social network who is "lower" than oneself is done using two "non-respect" 10 forms - qii "non-respected female' and $b a k^{2}$ 'non-respected male'. (These are not kinship terms themselves.) Thus, while a girl (named sèeng ${ }^{3}$ ) will refer to her grandmother (named $s i i^{3}$ ) as $t u^{0}$-sii 'Grandma Sii', the girl will be referred to in return as $q i^{0}$-sèeng ${ }^{3}$ 'the non-respected female Sèng', and not as, say * laan $^{3}$-sèeng ${ }^{3}$ (where $\operatorname{laan}^{3}$ means 'grandchild'). Like the kinship terms just discussed (see Table 10), these terms are used as heads in modifier expressions (involving demonstratives, adjectives, or relative clauses), but are not used as numeral classifiers.

The gender-specific "non-respect" forms $q i^{1}{ }^{1}$ 'non-respected female' and $b a k^{2}$ 'nonrespected male' are also sometimes used as prefixes to certain non-human nouns whose referents are not inherently of one or the other sex (such as certain kinds of animals, insects, and artefacts). They appear (sometimes optionally) as prefixes to a restricted set of

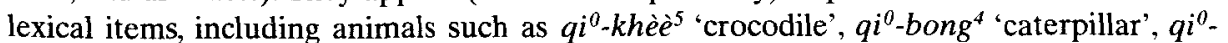
piing 'leech', and games such as $q i^{0}$-jaang 'skip-rope' (where the 'rope' is made of rubber bands -jaang ${ }^{3}$ means 'rubber') and $n a j^{2} q i^{0}{ }^{0}$ khaam $^{3}$ 'tamarind-seed checkers' (where $n a j^{2}$ means 'seed' and khaam ${ }^{3}$ means 'tamarind'). In the latter case, the playing pieces are anaphorically referred to using the female non-respect term $q i i^{l}$ in modifier classifier func-

10 "Respect" and "politeness" are complex and difficult to characterise, especially due to the interaction between semantics and pragmatics in this domain. "Non-respect" does not entail "disrespect". In the Lao-speaking community, there are extensive social rules for showing respect linguistically, and linguistic semantics provides rich means for doing so. To use someone's name alone is to semantically say nothing about the level of respect being given, but this may have pragmatic import in the context of what could have been said (LEVINSON 2000: 35-36). The use of $q i i^{\prime}$ - and $b a k^{2}$ - as prefixes to personal names in address or third person reference explicitly states that you are not showing any of the possible available respect expressions. But this does not entail disrespect. It may imply it if a respect form is pragmatically called for in that context. Otherwise, the use is "intimate" or "familiar". 
tions. Finally, note that the "female" prefix $q i^{1}$ is used most unexpectedly as a prefix for two terms referring to male human referents, namely, $q i^{0}$-phò $\grave{o}^{I}$ 'daddy' (phò $\grave{o}^{1}$ means 'father') and $q i^{0}$-taa $a^{3}$ 'old fellow' ( $t a a^{3}$ means 'maternal grandfather').

In all cases of "extension" of the gender-specific non-respect forms (the feminine qii ${ }^{1}$ being more productive than the masculine term $b a k^{2}$ in this respect), the presence of the prefix has the effect of portraying the referent as something familiar (specifically, in some sense associated with taking a child's viewpoint - i.e. as children might speak with each other, or as an adult might speak to a child).

\section{On the relation between different forms of nominal classification in Lao}

AikHenvald (2000) suggests two ways in which a language can have more than one system of nominal classification. First, in a "multiple classifier language", "[t]he same, or almost the same, set of morphemes can be used in more than one classifier environment" (AikHENVALD 2000: 204). Otherwise, there will be "several distinct classifier types" coexisting in the language (AIKHENVALD 2000: 184). Available sources on nominal classification in Thai lead AIKHENVALD (2000:213) to the conclusion that Thai is a "multiple classifier language", using "one set of morphemes in four environments" (i. e. with numerals, with demonstratives, with other modifiers, and as class terms). However, as already stated in this paper, the distribution of nominal classification devices in Lao is not essentially different to that in Thai, and it should be clear from the discussion in $\$ 2-\$ 5$, above, that the three major systems of numeral classifiers, modifier classifiers, and class terms do not draw upon "the same set of morphemes". ${ }^{11}$ Descriptions of Thai have tended to treat "classifiers" as a unitary system, but have concentrated on numeral classifier contexts, without noting the phonological, syntactic, and semantic differences between classifiers in numeral classifier and modifier classifier contexts. (CARPENTER 1986 is an important exception.) As for the class terms (cf. $\S 4$, above), there is significant disjunction between these and other classifiers such as numeral classifiers. Let me briefly discuss the Lao case.

It was established in $\S 2$ and $\S 3$, above, that speakers make quite different choices of classifiers in the numeral classifier and modifier classifier contexts. While most numeral classifiers can theoretically be used in either context, in practice the use of particular classifiers with particular nouns is quite different in the two systems. The most common modifier classifiers, $\operatorname{too}^{3}$ 'body' and qan $^{3}$ 'small thing', have much more general meanings in modifier classifier functions than in numeral classifier functions, and, accordingly, can be used with a much greater range of nouns in the former function. In addition, there is at least one classifier ( $p h u u^{5}$ 'person') that is restricted to the modifier classifier function only.

The class term system includes many elements which cannot be used as numeral classifiers at all. The following example shows that while all fish names include a class term which is a bound and reduced form of $\mathrm{paa}^{3}$ 'fish', this term cannot be used as a numeral classifier for fish:

$\begin{array}{lll} & { }^{*} p a^{0}-d u k^{2} & \text { sò̀ng } \\ \text { CT.FISH-sp. } & \text { two } & \text { fish } \\ \text { (two catfish) } & & \end{array}$

${ }^{11}$ Kin prefixes clearly form a distinct system and are not discussed in this section. 
Instead, the classifier for non-human animates - $t o o^{3}$ 'body' - must be used:

$\begin{array}{llll}\text { (77) } & p a^{0}-d u k^{2} & \text { sòong } & \\ \text { cT.FISH-sp. } & \text { two } & \text { CLF.ANIM } \\ \text { 'two catfish' } & & \end{array}$

This is not surprising, given that class terms and numeral classifiers have different semantics appropriate to their different functions. Class terms in Lao refer to taxonomic "essence", while numeral classifiers generally refer to shape/form and/or functional properties (or are assigned by convention).

This being said, one can certainly find examples in which the class term and numeral classifier are the same morpheme (though with a stress/intonational difference associated with the fact that the class term is phonologically dependent on a following stressed element):

$$
\begin{aligned}
& \text { mit }^{2} \quad \text { pòng }{ }^{0} \text {-qiam }{ }^{4} \quad c^{2} k^{2} \quad \text { pò̀ng }{ }^{l} \\
& \text { there.is CT.OPENING-window how.many CLF.OPENING } \\
& \text { 'How many windows are there?' } \\
& \quad c a k^{2} \quad t a a^{3}
\end{aligned}
$$

(79) $t a^{0}-k a a^{4}$

The set of classifiers used in the numeral classifier and class term systems show only partial overlap.

Thus, Lao presents an example of what AIKHENVALD (2000:184) calls "different classifier types in one language", and, given more careful examination, the same would surely be said about the Thai system.

\section{Summary}

The following table summarises the various types of nominal classification in Lao described in this paper:

\begin{tabular}{|l|l|l|l|l|l|l|}
\hline & $\begin{array}{l}\text { Numeral } \\
\text { classifiers }\end{array}$ & \multicolumn{3}{|l|}{ Modifier classifiers } & Class terms & Kin prefixes \\
\hline & a. unitizing & $\begin{array}{l}\text { b.demon- } \\
\text { strative }\end{array}$ & c. modified & & \\
\hline $\begin{array}{l}\text { Functional } \\
\text { context }\end{array}$ & counting & unitizing & $\begin{array}{l}\text { situational } \\
\text { or discourse } \\
\text { deixis, } \\
\text { anaphora }\end{array}$ & $\begin{array}{l}\text { unitizing, } \\
\text { hosting } \\
\text { modifica- } \\
\text { tion }\end{array}$ & $\begin{array}{l}\text { lexically } \\
\text { derivational }\end{array}$ & $\begin{array}{l}\text { social deixis } \\
\text { for personal } \\
\text { reference }\end{array}$ \\
\hline $\begin{array}{l}\text { Grammati- } \\
\text { cal context }\end{array}$ & NUM_- & - NOM & - DEM & $\begin{array}{l}\text {-ADJ/ } \\
\text { REL.CLS }\end{array}$ & - MOD & - NAME \\
\hline $\begin{array}{l}\text { Phono- } \\
\text { logical } \\
\text { status }\end{array}$ & stressed & \multicolumn{6}{|c|}{ unstressed, dependent } \\
\hline
\end{tabular}


Continue Table 11

\begin{tabular}{|l|l|l|l|l|l|}
\hline & $\begin{array}{l}\text { Numeral } \\
\text { classifiers }\end{array}$ & \multicolumn{2}{|l|}{ Modifier classifiers } & Class terms & Kin prefixes \\
\hline $\begin{array}{l}\text { Semantic } \\
\text { properties }\end{array}$ & $\begin{array}{l}\text { fine seman- } \\
\text { tic contrast, } \\
\text { encoding } \\
\text { shape/form, } \\
\text { function; } \\
\text { variable } \\
\text { assignment; } \\
\text { object of } \\
\text { speaker } \\
\text { awareness }\end{array}$ & $\begin{array}{l}\text { only refer } \\
\text { to shape/ } \\
\text { form of unit }\end{array}$ & $\begin{array}{l}\text { semantic specificity un- } \\
\text { necessary in these func- } \\
\text { tions; distinctions often } \\
\text { neutralized (using just } \\
\text { too } \\
\text { 'small thing'), and use of } \\
\text { more specific terms in } \\
\text { these contexts is prag- } \\
\text { matically marked }\end{array}$ & $\begin{array}{l}\text { refer to taxo- } \\
\text { nomic } \\
\text { 'essence' }\end{array}$ & $\begin{array}{l}\text { refer to } \\
\text { higher' } \\
\text { kinship } \\
\text { relation, } \\
\text { mark ex- } \\
\text { pression of } \\
\text { respect }\end{array}$ \\
\hline $\begin{array}{l}\text { Approxi- } \\
\text { mate size } \\
\text { of set }\end{array}$ & \begin{tabular}{l}
$100+$ \\
\hline
\end{tabular} & $20+$ & 2-100+ & $20+$ & $10+$ \\
\hline
\end{tabular}

Table 11: Summary of systems of nominal classification in Lao

The aim of this paper has been to describe the basic grammar of nominal classification in Lao, in terms of recent advances in the universal morphosyntactic typology of classifiers and related phenomena (Aikhenvald 2000, Grinevald 2000). It is clear that different subsystems of broader systems of nominal classification have distinct communicative functions, and as such each subsystem has its own independent synchronic reasons for existence, despite possible hypotheses as to the status of one subsystem as an "extension" of another. To more accurately characterise the functions of classifiers and the nature of their diachronic tendencies, the existing body of research focussed on morphosyntactic distinctions in nominal classification must now be complemented with careful cross-linguistic investigation of how systems of nominal classification are actually used in discourse and interaction.

\section{Abbreviations}

The transliteration of Lao used here follows IPA standard except for the following:

$\begin{array}{lll}\text { schwa } & \grave{u} & \text { high back unrounded vowel } \\ \text { high-mid front vowel } & n g & \text { velar nasal } \\ \text { low front vowel } & \tilde{n} & \text { palatal nasal } \\ \text { low back vowel } & q & \text { glottal stop }\end{array}$

Lexical tone is indicated by superscript numeral, as follows:

mid level (33)

high rising (35)

low rising (13)

high falling (51)

low falling (31)

Interlinear glosses are as follows:

$\begin{array}{llll}1 / 2 / 3 & 1^{\text {st } / 2^{\text {nd }} / 3^{\text {rd }} \text { person }} & \text { FOC } & \text { focus } \\ \text { ANIM } & \text { animals } & \text { GEN } & \text { general } \\ \text { CLF } & \text { classifier } & \text { HUM } & \text { human } \\ \text { CT } & \text { class term } & \text { IRR } & \text { irrealis } \\ \text { DEM } & \text { demonstrative } & \text { NEG } & \text { negation }\end{array}$




$\begin{array}{llll}\text { NONP } & \text { non-polite } & \text { REL } & \text { relativiser } \\ \text { NONPROX } & \text { non-proximal } & \text { SG } & \text { singular } \\ \text { P } & \text { polite } & \text { sp } & \text { species } \\ \text { PCL } & \text { particle } & \text { TPC } & \text { topic } \\ \text { PL } & \text { plural } & & \end{array}$

\section{References}

Aikhenvald, Alexandra Y. (2000): Classifiers: a typology of noun categarization devices. Oxford: Oxford University Press.

AllaN, KeITH (1977): Classifiers, in: Language 53, 284-310.

Carpenter, Kathie (1986): Productivity and pragmatics of Thai classifiers, in: Proceedings of the Twelfth Annual Meeting of the Berkeley Linguistics Society, 14-25.

ENFIELD, N. J. (1999): Lao as a national language, in: Evans, Grant (ed.), Laos: culture and society. Chiang Mai: Silkworm Books, 258-290.

ENFIELD, N. J. (2003): Linguistic epidemiology: semantics and grammar of language contact in mainland Southeast Asia. London: Routledge.

Enfield, N. J. (forthcoming): Depictive secondary predicates in Lao, in: HimmelmanN, Nikolaus P. \& Schultze-Berndt, Eva (eds.), Secondary predication and adverbial modification: crosslinguistic explorations in the syntax and semantics of depictives. Oxford: Oxford University Press.

GIL, DAVID (1987): Definiteness, noun phrase configurationality, and the count-mass distinction, in: REUland, Eric J. \& Ter Meulen, Alice G. B. (eds.), The representation of (in) definiteness. Cambridge, Mass./London, England: MIT Press, 254-269.

Grinevald, Coletre (1993): A typology of nominal classification. Paper presented at workshop 'Back to basic issues in nominal classification'. Max Planck Institute for Psycholinguistics, Nijmegen.

Grinevald, Colette (1996): A typology of classifiers: issues and perspectives. Plenary paper presented at the Third Australian Linguistic Institute, Canberra July 4, 1996.

Grinevald, Coletre (2000): A morphosyntactic typology of classifiers, in: Senft, Gunter (ed.), Systems of nominal classification. Cambridge: Cambridge University Press, 50-92

Hundius, Harald \& Kölver, Ulrike (1983): Syntax and semantics of numeral classifiers in Thai, in: Studies in Language 7.2,165-214.

Juntanamalaga, Preecha (1988): Social issues in Thai classifier usage, in: Language Sciences 10,313-30.

Kerr, Alan D. (1972): Lao-English dictionary. Washington DC: Catholic University of America Press.

LEVINSON, STEPHEN C. (2000): Presumptive meanings: the theory of generalised conversational implicature. Cambridge, Mass./London, England: MIT Press.

Photchani, SiRIAKsornsastr (1993): The source and development of two-syllable words beginning with kra- and ka- in Thai. Chulalongkorn University MA Thesis (in Thai).

SAGART, LAURENT (2001): Vestiges of Archaic Chinese derivational affixes in Modern Chinese dialects, in: Chappell, Hilary (ed.), Sinitic grammar: synchronic and diachronic perspectives. Oxford: Oxford University Press, 123-142.

Sackmann, Robin (2000): Numeratives in Mandarin Chinese, in: Vogel, Petra M. \& Comrie, Bernard (eds.), Approaches to typology of word classes. Berlin: Mouton de Gruyter, 421-478.

N. J. ENFIELD

Language and Cognition Group

Max Planck Institute for Psycholinguistics

PB 310

$6500 \mathrm{AH}$, Nijmegen

THE NETHERLANDS

nick.enfield@mpi.nl 